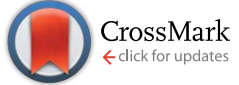

Cite this: RSC Adv., 2014, 4, 32647

\title{
A new route to nanoscale ceramics in asymmetric reaction fields of carbon nanospaces $\uparrow$
}

\author{
Tomonori Ohba, ${ }^{*}$ Yuki Ohyama and Hirofumi Kanoh
}

Received 4th June 2014

Accepted 18th July 2014

DOI: 10.1039/c4ra05311g

www.rsc.org/advances

We fabricated nanoscale $\mathrm{BaTiO}_{3}$ and its asymmetric crystal structure was obtained using an asymmetric reaction field in carbon nanospaces. The nano-crystal phases changed from symmetric to asymmetric crystals with decreasing crystallite size. The fabrication of an asymmetric crystal in a nanospace can be adapted for various ceramic fabrications.

The fabrication of nanoscale materials (nanomaterials) has attracted attention in fundamental and applied research, because nanomaterials have very different physical properties from those of single crystals and coarse-grained polycrystals. ${ }^{1,2}$ The interfaces of nanomaterials are primarily responsible for their novel properties, based on high reactivities and large surface areas..$^{3-6}$ Control of these interfaces or the grain size is therefore necessary for the preparation of widely applicable nanomaterials. ${ }^{7,8}$ Barium titanate $\left(\mathrm{BaTiO}_{3}\right)$, a perovskite-type material, is one of the most common electronic ceramic materials because it can be used in electro-optic devices, capacitors, and transducers. Nanoscale $\mathrm{BaTiO}_{3}$ is expected to have novel structural and physical properties: grain-size dependence of structural transformations and lowering of the Curie temperature with decreasing grain size. ${ }^{9-12}$ The design of nanoscale $\mathrm{BaTiO}_{3}$ has contributed to significant developments in ferroelectrics and the miniaturization of electronic devices. Much attention has focused on the preparation of nanoscale $\mathrm{BaTiO}_{3}$ by hydrothermal, solvothermal, sol-gel, and chemical precipitation methods instead of $\mathrm{BaTiO}_{3}$ crystal preparation by hightemperature solid-state reactions. ${ }^{13-17}$ Sol-gel and sol-gel solvothermal reactions have the advantage of uniform nanoscale crystal productions. ${ }^{10,13,18,19}$ Here, we describe size-dependent

Graduate School of Science, Chiba University, 1-33 Yayoi, Inage, Chiba 263-8522, Japan.E-mail: ohba@pchem2.s.chiba-u.ac.jp

$\dagger$ Electronic supplementary information (ESI) available: Schematic image of preparation of $\mathrm{BaTiO}_{3}$, characterization of confined- $\mathrm{BaTiO}_{3}$, microscopic images of $\mathrm{BaTiO}_{3}, \mathrm{~N}_{2}$ adsorption isotherms of $\mathrm{BaTiO}_{3}$ samples at $77 \mathrm{~K}$, those XRD patterns, simulated XRD patterns, and Raman Spectroscopy. See DOI: 10.1039/c4ra05311g nanocrystalline phases of $\mathrm{BaTiO}_{3}$ and $\mathrm{BaTiO}_{3}$ with an anomalous structure, prepared under asymmetric reaction fields in the nanospaces of activated carbon fibers (ACFs), which are known to have abundant carbon nanospaces, with strong molecular fields for adsorption, separation, storage, and chemical reactions. ${ }^{20-22}$ A sol-gel solvothermal method was adopted for preparation of nanoscale $\mathrm{BaTiO}_{3}$ confined in nanospaces of ACFs, because the subnanometer scale precursor by a sol-gel method could enter into those nanospaces. ${ }^{17}$

Crystalline- $\mathrm{BaTiO}_{3}$ was prepared using a solid-state reaction by heating at $1473 \mathrm{~K}$ (see the Supplementary Information for details). The powder XRD pattern of crystalline- $\mathrm{BaTiO}_{3}$ (Fig. 1a) showed a highly crystalline $\mathrm{BaTiO}_{3}$ structure without any impurities, and matched previously reported patterns..$^{23,24}$ The crystallite size of crystalline- $\mathrm{BaTiO}_{3}$ was $1270 \mathrm{~nm}$, decided from the SEM images. Solid-state reactions at 1073 and $1173 \mathrm{~K}$ also produced $\mathrm{BaTiO}_{3}$ crystals (micro- $\mathrm{BaTiO}_{3}$ ) without impurities, but the peaks in the XRD patterns were wider than those for crystals prepared at $1473 \mathrm{~K}$, as shown in Fig. 1b. The crystallite sizes for micro-BaTiO ${ }_{3}$ preparation at 1073 and $1173 \mathrm{~K}$ were 94 and $110 \mathrm{~nm}$, respectively, evaluated from the XRD peaks using the Scherrer equation. ${ }^{25,26}$ The crystallite sizes of micro$\mathrm{BaTiO}_{3}$ were apparently smaller than that of crystalline-BaTiO${ }_{3}$. Thus, crystallite size could be controlled by the heating temperature in solid-state reactions. Fig. 1c shows XRD patterns of $\mathrm{BaTiO}_{3}$ crystals (nano-BaTiO${ }_{3}$ ) prepared by a sol-gel method at $400 \mathrm{~K}$ using a Ti concentration of $50-400 \mathrm{mM}$. The crystal sizes of nano- $\mathrm{BaTiO}_{3}$ were approximately $5 \mathrm{~nm}$. The XRD pattern peaks of confined- $\mathrm{BaTiO}_{3}$ were further broadened, as shown in Fig. 1d, because these $\mathrm{BaTiO}_{3}$ crystals are nanoscale. The XRD patterns also included peaks from ACFs. The XRD pattern of ACF had broad peaks corresponding to the 002 and 10 layers of graphitic materials, with crystallite sizes of 1.8 and $4.1 \mathrm{~nm}$, respectively, determined using the Scherrer equation. Thus, the in-plane size of graphitic unit was $4.1 \mathrm{~nm}$, as shown in Fig. S2c. $\dagger$ The average crystallite sizes of crystalline, micro-, nano-, and confined-BaTiO ${ }_{3}$ are summarized in Fig. 1e. $\mathrm{BaTiO}_{3}$ confined in nanospaces gave crystals smaller than $3 \mathrm{~nm}$ under 

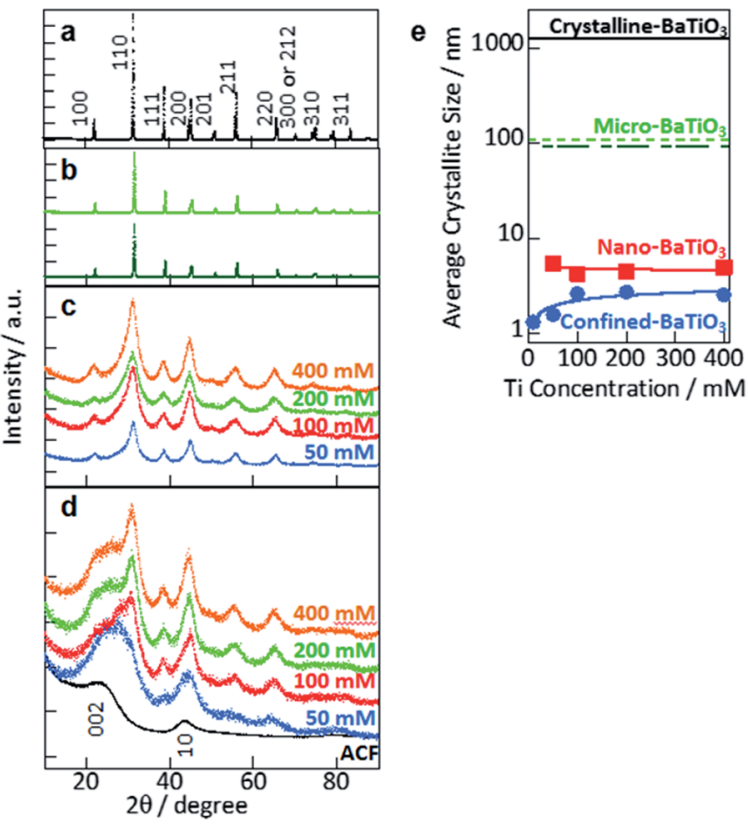

Fig. 1 XRD patterns of crystalline- $\mathrm{BaTiO}_{3}(\mathrm{a})$, micro- $\mathrm{BaTiO}_{3}(\mathrm{~b})$, nano$\mathrm{BaTiO}_{3}$ (c), and confined-BaTiO 3 (d). XRD patterns of crystalline$\mathrm{BaTiO}_{3}$ and $\mathrm{ACF}$ are shown for comparison. All peaks were assigned to $\mathrm{BaTiO}_{3}$ crystals. Broad patterns originating from ACF were also present in the XRD patterns of confined-BaTiO 3 . (e) Average crystallite sizes of crystalline-, micro-, nano-, and confined- $\mathrm{BaTiO}_{3}$, determined from main peaks using Scherrer equation. Average crystallite size of crystalline- $\mathrm{BaTiO}_{3}$ evaluated from SEM observations was used as a standard.

all preparation conditions. Specifically, the crystallite sizes were nearly $1 \mathrm{~nm}$ when the Ti concentrations were weaker than $50 \mathrm{mM}$. This is a result of confined effect in nanospaces. The unit sizes of these nanospaces were approximately $4.1 \times 4.1 \times$ $1.3 \mathrm{~nm}^{3}$ (a schematic image of confined-BaTiO ${ }_{3}$ is shown in Fig. $\mathrm{S} 2 \dagger)$. The $\mathrm{BaTiO}_{3}$ crystals were therefore smaller than $3.6 \mathrm{~nm}$ when the crystals were prepared in nanospaces, despite the same preparation method. In other words, the crystal sizes of confined- $\mathrm{BaTiO}_{3}$ were restricted to less than $3.6 \mathrm{~nm}$, although the preparation method was the same as for nano- $\mathrm{BaTiO}_{3}$, with crystallite sizes of $5 \mathrm{~nm}$. The crystal sizes of nanoscale ceramics can therefore be controlled by choosing nanospaces of appropriate sizes.

The $\mathrm{BaTiO}_{3}$ crystals were observed using TEM and SEM, as shown in Fig. 2 and $\mathrm{S} 3 . \dagger \mathrm{BaTiO}_{3}$ crystals prepared by a solidstate reaction at $1173 \mathrm{~K}$, a sol-gel solvothermal reaction using a Ti concentration of $50 \mathrm{mM}$, and a sol-gel solvothermal reaction in nanospaces using a Ti concentration of $50 \mathrm{mM}$ were used as crystalline-, micro-, nano-, and confined-BaTiO ${ }_{3}$, respectively. Crystalline- and micro- $\mathrm{BaTiO}_{3}$ were cuboid or polyhedral, but nano- and confined- $\mathrm{BaTiO}_{3}$ were roughly spherical. Electron diffraction showed spot patterns for crystalline- $\mathrm{BaTiO}_{3}$, spot and ring patterns for micro-BaTiO ${ }_{3}$, and only ring patterns for nano- and confined- $\mathrm{BaTiO}_{3}$. These patterns are roughly typical of tetragonal-phase $\mathrm{BaTiO}_{3}$. Energydispersive spectroscopy mapping showed that these particles

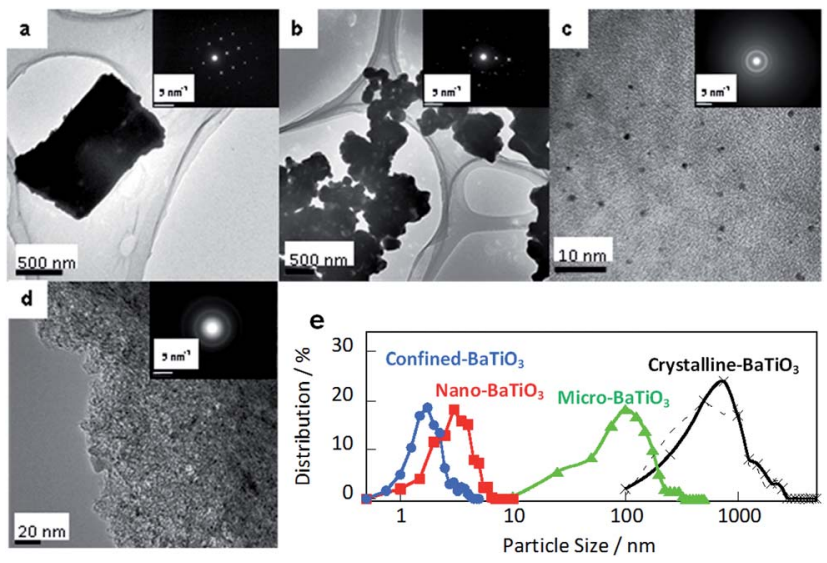

Fig. 2 TEM images of crystalline- $\mathrm{BaTiO}_{3}$ (a), micro- $\mathrm{BaTiO}$ (b), nano$\mathrm{BaTiO}_{3}$ (c), and confined-BaTiO 3 (d). Electron diffraction patterns are inserted in each image. All electron diffraction patterns have peaks from $\mathrm{BaTiO}_{3}$. The electron diffraction patterns changed from spots to ring patterns with decreasing $\mathrm{BaTiO}_{3}$ particle size. (e) Particle size distributions of $\mathrm{BaTiO}_{3}$ obtained from 200 to 300 particles. Dashed curve represents particle size distribution of crystalline- $\mathrm{BaTiO}_{3}$ evaluated from $\mathrm{BaTiO}_{3}$ particles in SEM images. Particle sizes of crystalline-, micro-, nano-, and confined-BaTiO 3 were $800 \pm 520$, $110 \pm 65,3.3 \pm 1.3$, and $1.8 \pm 0.6 \mathrm{~nm}$, respectively.

consist of $\mathrm{Ba}$, Ti, and $\mathrm{O}$ (Fig. $\mathrm{S} 3 \dagger$ ). For confined- $-\mathrm{BaTiO}_{3}, \mathrm{Ba}$, Ti, and $\mathrm{O}$ were also found in the ACFs. The particle size distributions in Fig. 2e were calculated from more than 200 particles of each type of $\mathrm{BaTiO}_{3}$ crystal in TEM images, assuming spherical particles. The particle sizes were approximately $800 \pm 520,110$ $\pm 65,3.3 \pm 1.3$, and $1.8 \pm 0.6 \mathrm{~nm}$ for crystalline-, micro-, nano-, and confined-BaTiO ${ }_{3}$, respectively, calculated on the assumption of a Gaussian distribution; the average sizes were 1060, 137, 3.6, and $2.1 \mathrm{~nm}$, respectively. The obtained particle sizes correspond well to the crystallite sizes from XRD analysis in Fig. 1e. The particle sizes were also evaluated from the Brunauer-Emmett-Teller surface areas obtained from $\mathrm{N}_{2}$ adsorption isotherms, and assuming spherical particles, as shown in Fig. S4. $\dagger$ The average particle sizes were $750,150,3.1$, and $3.6 \mathrm{~nm}$ for crystalline-, micro-, nano-, and confined-BaTiO ${ }_{3}$, respectively. The particle sizes evaluated from TEM, SEM, and $\mathrm{N}_{2}$ adsorption isotherms agree well with the crystallite sizes obtained using XRD for the corresponding crystals, as shown in Fig. S4d $\dagger$ (details are shown in Fig. S5†). The crystal sizes obtained using XRD were therefore supported by particle size evaluation using TEM, SEM and $\mathrm{N}_{2}$ adsorption isotherms.

The peak positions of the XRD profiles were slightly shifted to lower angles when the crystal size decreased (Fig. 1 and S5†). The lower angle shifts of the peak positions indicated that the corresponding lattice spaces were expanded. The relationships between crystallite size and lattice space are shown in Fig. 3a. The (222) and (220) layers rarely changed in crystalline- and micro-BaTiO $_{3}$ (crystallite size less than $90 \mathrm{~nm}$ ), whereas the (200) layer of micro-BaTiO ${ }_{3}$ expanded by $0.4 \%$ to give a cubic form, as discussed later. All the lattice spaces of nano-BaTiO (crystallite size between 5 and $30 \mathrm{~nm}$ ) expanded by nearly 1\%, and the (222) and (220) layers expanded significantly in 


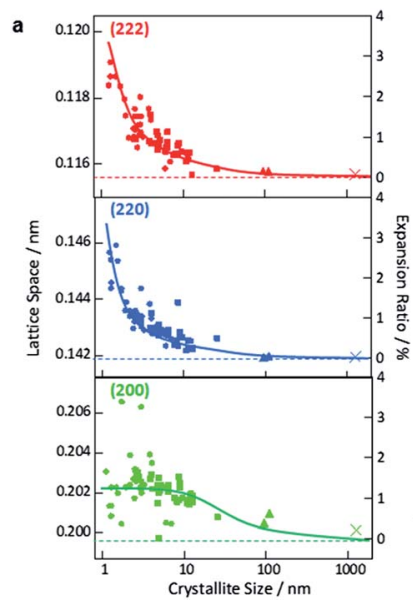

b

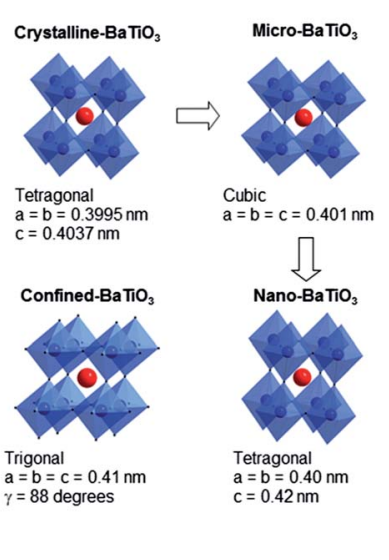

Fig. 3 (a) Lattice spaces of (222), (220), and (200) planes and expansion ratios to $\mathrm{BaTiO}_{3}$ in the cubic phase as function of crystallite size. The unit cell size of cubic $\mathrm{BaTiO}_{3}$ is $0.3996 \mathrm{~nm}$. : confined- $\mathrm{BaTiO}_{3}$, nano- $\mathrm{BaTiO}_{3}, \mathbf{\Delta}$ : micro- $\mathrm{BaTiO}_{3}$, and $\times$ : crystalline-BaTiO Dashed lines represent lattice spaces in cubic phase of $\mathrm{BaTiO}_{3}$. Significant increases in lattice space sizes were observed with decreasing crystallite size for (222) and (220) directions, whereas approximately $1 \%$ expansion in the (200) direction was observed for crystallites smaller than $100 \mathrm{~nm}$. (b) Structure dependence on crystallite size of $\mathrm{BaTiO}_{3}$. Crystalline-, micro-, nano-, and confined-BaTiO have tetragonal, cubic, tetragonal, and trigonal phase structures, respectively.

confined- $\mathrm{BaTiO}_{3}$ (crystallite size less than $3 \mathrm{~nm}$ ), although the (200) layer rarely changed to that of nano- $\mathrm{BaTiO}_{3}$. These results suggest that $\mathrm{BaTiO}_{3}$ nanocrystals such as nano- and confined$\mathrm{BaTiO}_{3}$ form anomalous phases or crystal structures. The crystal structures of representative $\mathrm{BaTiO}_{3}$ crystals, which were the same as those used in the TEM observations, were determined by fitting simulated XRD patterns to the experimental ones (Fig. S6 $\dagger$ ). Crystalline-, micro-, nano-, and confined-BaTiO ${ }_{3}$ have the tetragonal phase with the $P 4 / \mathrm{mmm}$ space group, cubic phase with the $P m 3 m$ space group, tetragonal phase with the $P 4 / \mathrm{mmm}$ space group, and trigonal phase with the $R 3 \mathrm{~m}$ space group, respectively. The peak widths were corrected using the Scherrer equation based on the experimental crystallite sizes. The peak positions for all $\mathrm{BaTiO}_{3}$ crystals coincided with each other in experimental and simulated XRD patterns. The crystalline$\mathrm{BaTiO}_{3}$ (size $1000 \mathrm{~nm}$ ) had a tetragonal phase $(a=b=0.3995$ $\mathrm{nm}$ and $c=0.4037 \mathrm{~nm}$ ), corresponding to reported values. ${ }^{27,28}$ The crystal structure of micro- $\mathrm{BaTiO}_{3}(100 \mathrm{~nm}$ in size) was transformed to the cubic phase $(a=b=c=0.401 \mathrm{~nm})$. Structural transformations from tetragonal to cubic phases with decreasing crystallite size have also been reported elsewhere. ${ }^{29}$ However, nano- $\mathrm{BaTiO}_{3}$ (size $5-30 \mathrm{~nm}$ ) had a tetragonal phase, like crystalline- $\mathrm{BaTiO}_{3}$, but larger crystal parameters $(a=b=$ $0.40 \mathrm{~nm}$ and $c=0.42 \mathrm{~nm})$. The confined-BaTiO $3($ size $1-3 \mathrm{~nm})$ was assigned a trigonal phase $\left(a=b=c=0.41 \mathrm{~nm}\right.$ and $\left.\gamma=88^{\circ}\right)$. The trigonal phase is usually observed below $200 \mathrm{~K}$ for $\mathrm{BaTiO}_{3}$ crystals. ${ }^{30-32}$ A novel trigonal structure was therefore observed at room temperature for nanoscale $\mathrm{BaTiO}_{3}$. The appearance of the trigonal structure could be the result of two effects: nanosized

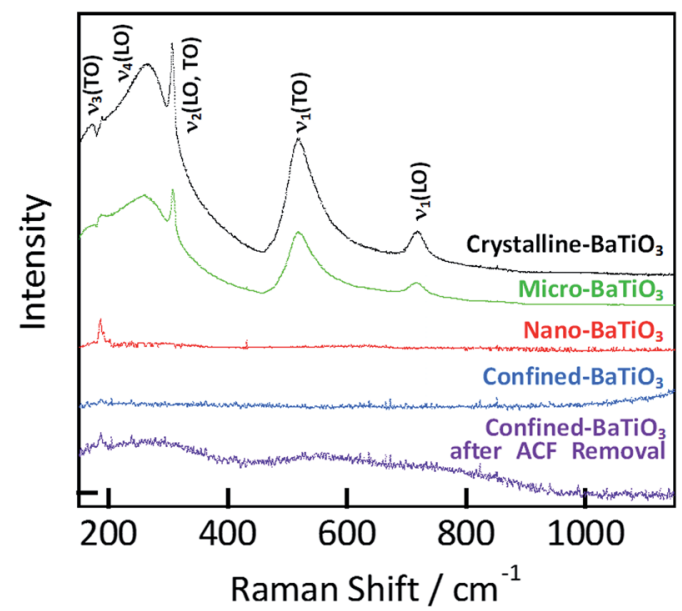

Fig. 4 Evaluation of $\mathrm{BaTiO}_{3}$ crystal phases using Raman spectroscopy.

crystal formation and an asymmetric reaction field in carbon nanospaces.

The $\mathrm{BaTiO}_{3}$ crystal structures were also examined using Raman spectroscopy (Fig. 4). ${ }^{29,31,33}$ Crystalline-BaTiO ${ }_{3}$ has the typical $\mathrm{BaTiO}_{3}$ peaks in the tetragonal phase: $\nu_{1}(\mathrm{LO})=720$ $\mathrm{cm}^{-1}, \nu_{1}(\mathrm{TO})=520 \mathrm{~cm}^{-1}, \nu_{2}(\mathrm{LO}, \mathrm{TO})=307 \mathrm{~cm}^{-1}$, and $\nu_{4}(\mathrm{LO})=$ $267 \mathrm{~cm}^{-1}$. The peaks for the $\nu_{1}(\mathrm{TO})$ and $\nu_{4}(\mathrm{LO})$ modes are unchanged for micro-BaTiO ${ }_{3}$, whereas those for the $\nu_{1}(\mathrm{LO})$ and $\nu_{2}(\mathrm{LO}, \mathrm{TO})$ modes decrease significantly, suggesting a cubic phase in micro-BaTiO ${ }_{3}$. Some Raman activities of the peaks for the $\nu_{1}(\mathrm{LO})$ and $\nu_{2}(\mathrm{LO}, \mathrm{TO})$ modes decrease as a result of $\mathrm{Ti}$ disorder in the nominal cubic phase. For nano- $\mathrm{BaTiO}_{3}$, only the sharp peak for the $\nu_{3}(\mathrm{TO})$ mode is observed. Confined-BaTiO ${ }_{3}$ has no obvious peaks in the Raman spectrum. However, after removal of ACFs by combustion at $673 \mathrm{~K}$ for $48 \mathrm{~h}$, a small sharp peak for the $\nu_{3}(\mathrm{TO})$ mode and broad peaks for the $\nu_{4}(\mathrm{LO}), \nu_{1}(\mathrm{TO})$, and $\nu_{1}(\mathrm{LO})$ modes $^{9}$ appear. These peaks are assigned to the trigonal phase of the $\mathrm{BaTiO}_{3}$ crystal and verify the presence of $\mathrm{BaTiO}_{3}$ crystals in the carbon nanopores. The $\mathrm{BaTiO}_{3}$ crystals of nano- and confined-BaTiO ${ }_{3}$ had unique Raman spectral features; these peaks could not be simply assigned to bulk crystal phases, but the trigonal phase was expected for confined$\mathrm{BaTiO}_{3}$.

\section{Conclusions}

Our studies demonstrate the preparation of extremely small $\mathrm{BaTiO}_{3}$ crystals, with a crystallite size of approximately $1 \mathrm{~nm}$. The crystal phase exhibits structural diversity even at room temperature, from tetragonal to cubic, tetragonal, and trigonal phases, with decreasing crystal size, associated with anomalous expansion of lattice spaces. The appearance of an anomalous trigonal phase of $\mathrm{BaTiO}_{3}$ confined in carbon nanospaces is the result of nanocrystallization in an asymmetric reaction field in these nanospaces and anomalous stabilization of the $\mathrm{BaTiO}_{3}$ nanocrystals, because the trigonal phase is only observed below $200 \mathrm{~K}$ in typical $\mathrm{BaTiO}_{3}$ crystals. Carbon nanospaces provide a strong asymmetric reaction field; therefore, asymmetric 
structures appear as a result of symmetry collapse, leading to a cryogenic phase in this case. These findings are the first demonstration of the preparation of extremely small perovskitetype nanoceramics and structural diversity with decreasing crystallite size, and anomalous lattice expansion., ${ }^{9,33-35}$ This method for nanocrystal preparation and nanostructuration could be used to synthesize various ceramics. Further studies on the piezoelectric properties and photorefractive effects are necessary to assess the performance of nanoscale asymmetric $\mathrm{BaTiO}_{3}$.

TEM observations were performed at the Chemical Analysis Center, Chiba University. This research was supported by a JSPS KAKENHI Grant Number 26706001 and Research Fellowships from the Futaba Electronics Memorial Foundation, Foundation for the JGC-S Scholarship Foundation, Promotion of Ion Engineering, and Murata Science Foundation.

\section{Notes and references}

1 B. S. Guiton and P. K. Davies, Nat. Mater., 2007, 6, 586-591. 2 P. M. Rorvik, T. Grande and M. A. Einarsrud, Adv. Mater., 2011, 23, 4007-4034.

3 H. Goesmann and C. Feldmann, Angew. Chem., Int. Ed., 2010, 49, 1362-1395.

4 E. Roduner, Chem. Soc. Rev., 2006, 35, 583-592.

5 Y. Wang, J. Zhang and Y. Zhao, Nano Lett., 2007, 7, 31963199.

6 I. Szlufarska, A. Nakano and P. Vashishta, Science, 2005, 309, 911-914.

7 Z. Shen, Z. Zhao, H. Peng and M. Nygren, Nature, 2002, 417, 266-269.

8 I.-W. Chen and X.-H. Wang, Nature, 2000, 404, 168-171.

9 Z. Zhao, V. Buscaglia, M. Viviani, M. T. Buscaglia, L. Mitoseriu, A. Testino, M. Nygren, M. Johnsson and P. Nanni, Phys. Rev. B: Condens. Matter Mater. Phys., 2004, 70, 024107.

10 M. H. Frey and D. A. Payne, Phys. Rev. B: Condens. Matter Mater. Phys., 1996, 54, 3158-3168.

11 Y.-I. Kim, J. K. Jung and K.-S. Ryu, Mater. Res. Bull., 2004, 39, 1045-1053.

12 S.-G. Kwon, K. Choi and B.-I. Kim, Mater. Lett., 2006, 60, 979982.

13 S. O'. Brien, L. Brus and C. B. Murray, J. Am. Chem. Soc., 2001, 123, 12085-12086.

14 T. M. Stawski, S. A. Veldhuis, O. F. Göbel, J. E. Ten Elshof and D. H. A. Blank, J. Am. Ceram. Soc., 2010, 93, 3443-3448.
15 Y. Mao, S. Mao, Z.-G. Ye, Z. Xie and L. Zheng, Mater. Chem. Phys., 2010, 124, 1232-1238.

16 X. Zhu, J. Wang, Z. Zhang, J. Zhu, S. Zhou, Z. Liu and N. Ming, J. Am. Ceram. Soc., 2008, 91, 2683-2689.

17 T. M. Stawski, S. A. Veldhuis, R. Besselink, H. L. Castricum, G. Portale, D. H. A. Blank and J. E. ten Elshof, J. Phys. Chem. C, 2011, 115, 20449-20459.

18 Y. V. Kolen'ko, K. A. Kovnir, I. S. Neira, T. Taniguchi, T. Ishigaki, T. Watanabe, N. Sakamoto and M. Yoshimura, J. Phys. Chem. C, 2007, 111, 7306-7318.

19 M. Veith, S. Mathur, N. Lecerf, V. Huch, T. Decker, H. P. Beck, W. Eiser and R. Haberkorn, J. Sol-Gel Sci. Technol., 2000, 17, 145-158.

20 P. Simon and Y. Gogotsi, Nat. Mater., 2008, 7, 845-854.

21 S. Sircar, T. Golden and M. Rao, Carbon, 1996, 34, 1-12.

22 G. Che, B. B. Lakshmi, E. R. Fisher and C. R. Martin, Nature, 1998, 393, 346-349.

23 Y. Zhang, L. Wang and D. Xue, Power Technol., 2012, 217, 629-633.

24 D. Liu, Y. Yan and H. Zhou, J. Am. Ceram. Soc., 2007, 90, 1323-1326.

25 A. Patterson, Phys. Rev., 1939, 56, 978.

26 H. Borchert, E. V. Shevchenko, A. Robert, I. Mekis, A. Kornowski, G. Grübel and H. Weller, Langmuir, 2005, 21, 1931-1936.

27 J. Harada, T. Pedersen and Z. Barnea, Acta Crystallogr., Sect. A: Cryst. Phys., Diffr., Theor. Gen. Crystallogr., 1970, 26, 336344.

28 W.-S. Cho, J. Phys. Chem. Solids, 1998, 59, 659-666.

29 M. B. Smith, K. Page, T. Siegrist, P. L. Redmond, E. C. Walter, R. Seshadri, L. E. Brus and M. L. Steigerwald, J. Am. Chem. Soc., 2008, 130, 6955-6963.

30 G. Kwei, A. Lawson, S. Billinge and S. Cheong, J. Phys. Chem., 1993, 97, 2368-2377.

31 C. Perry and D. Hall, Phys. Rev. Lett., 1965, 15, 700-702.

32 P. W. Forsbergh Jr, Phys. Rev., 1949, 76, 1187.

33 V. Buscaglia, M. T. Buscaglia, M. Viviani, L. Mitoseriu, P. Nanni, V. Trefiletti, P. Piaggio, I. Gregora, T. Ostapchuk, J. Pokorný and J. Petzelt, J. Eur. Ceram. Soc., 2006, 26, 2889-2898.

34 S. Lin, T. Lü, C. Jin and X. Wang, Phys. Rev. B: Condens. Matter Mater. Phys., 2006, 74, 134115.

35 X. Wang, X. Deng, H. Wen and L. Li, Appl. Phys. Lett., 2006, 89, 162902-162903. 